\title{
Retrieval of a long foreign body from the stomach with a duodenoscope
}

Foreign body ingestion presents a common clinical problem facing gastroenterologists and surgeons. Most foreign bodies pass spontaneously but long objects in the range of $6-10 \mathrm{~cm}$ in length are less likely to pass the duodenal curve and often require removal from the stomach [1]. Endoscopic retrieval is challenging due to difficulties in orienting the object parallel to the esophagus in a secure fashion in order to facilitate removal through the lower esophageal sphincter (LES). We present a simple technique that avoided laparotomy in a patient presenting with a large retained gastric foreign body.

A 20-year-old female presented after intentionally swallowing a long metallic serving spoon. A plain film of the abdomen confirmed the presence of an $18-\mathrm{cm}$ spoon within the stomach ( $\bullet$ Fig. 1 ).

A replica of the object was obtained and a dry run performed ex-vivo. With a standard gastroscope, snaring the spoon flush against the tip positioned the object perpendicular to the scope in a " $\mathrm{T}$ " orientation ( Fig. 2), making removal through the LES extremely challenging.

Snaring the spoon with a duodenoscope with the elevator fully raised oriented the object parallel to the long axis of the scope, in appropriate alignment for removal ( $\bullet$ Fig. 2).

Esophagogastroduodenoscopy was performed, revealing a large metal spoon within the stomach ( $\bullet$ Fig. 3 ).

The gastroscope was exchanged for a duodenoscope and a snare was placed over the shaft of the spoon. Tension at the LES tightened the snare against the tapered body of the spoon, securing the object for retrieval. Using fluoroscopic guidance $(\bullet$ Figs. 4 and 5) and direct visualization, the scope was slowly withdrawn from the stomach.

The narrow end of the spoon entered the esophagus flush with the duodenoscope, and the remainder of the spoon followed (๑ Fig. 6).

Although $80 \%-90 \%$ of ingested foreign bodies pass spontaneously through the gastrointestinal tract, $10 \%-20 \%$ require endoscopic intervention and approximately $1 \%$ need surgical exploration and extraction [1]. Long foreign bodies pose a particular challenge due to difficulties in orienting and securing the object within

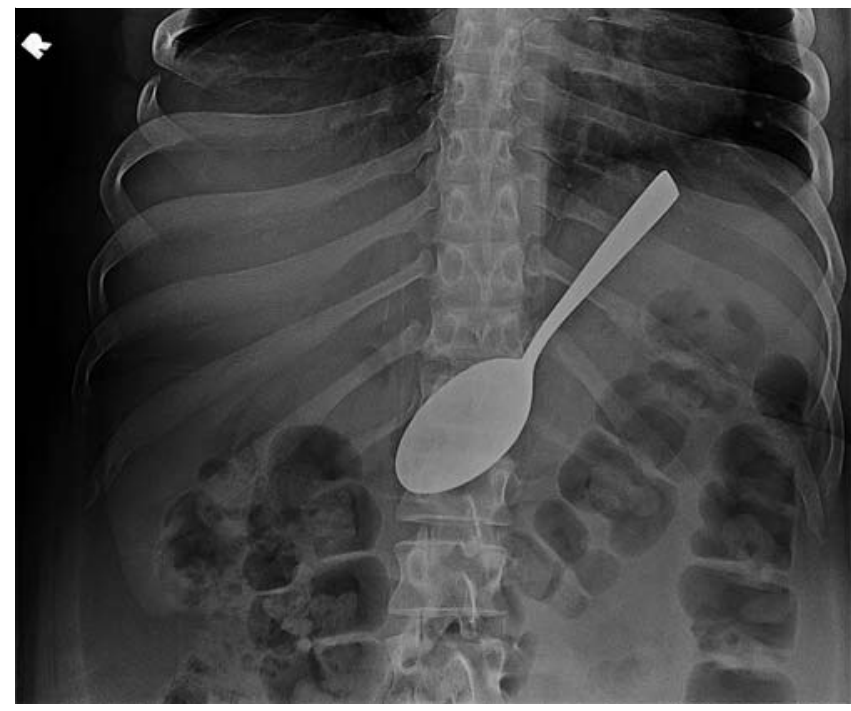

Fig. 1 Radiograph showing 18-cm spoon within the stomach.

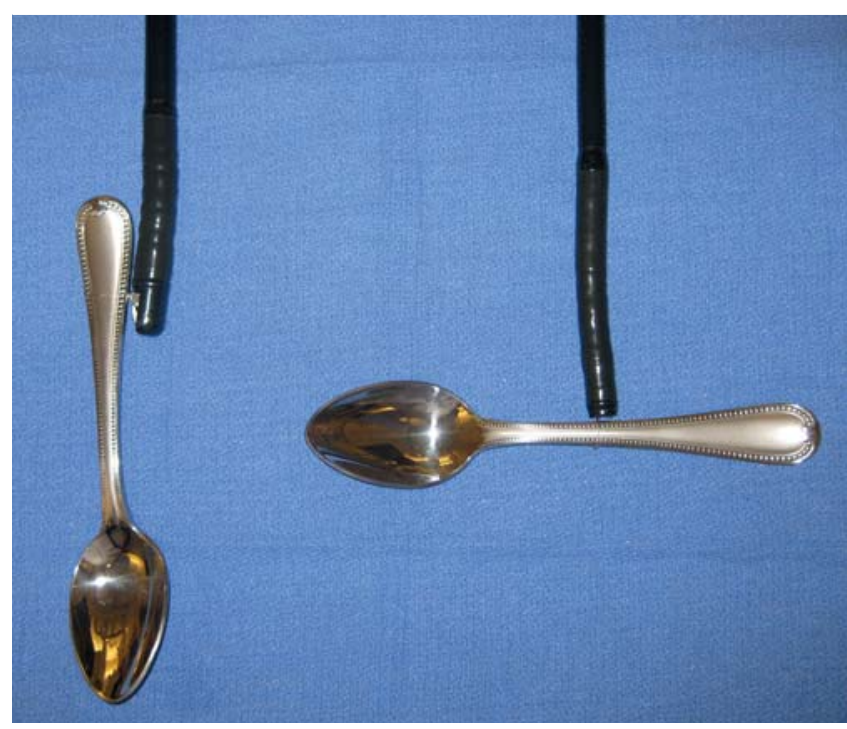

Fig. 2 A replica spoon was used to determine the best approach for snaring and retrieval.

the stomach. Several techniques have described the removal of long foreign bodies through the use of multiple snares, two simultaneous endoscopes, and balloontipped scopes [2-6]. We present a simplified technique using a side-viewing endoscope and one snare. This approach has never been described in the English literature. We believe that this is a safe and effective method that uses broadly available equipment, and should be considered by the skilled endoscopist in the right setting.

Endoscopy_UCTN_Code_TTT_1AO_2AL

Competing interests: None

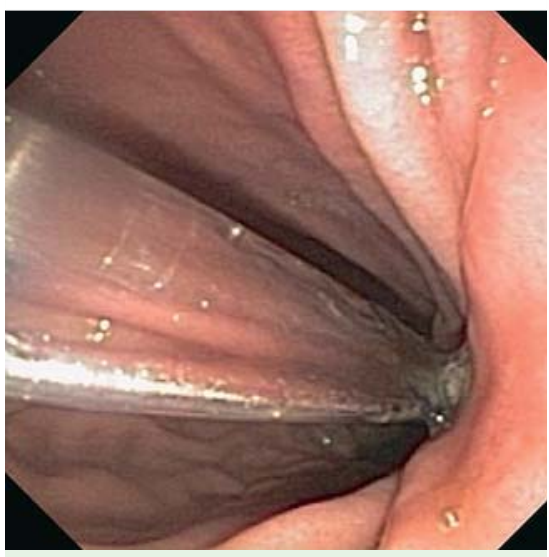

Fig. 3 Large metal spoon seen within the stomach on gastroscopy. 


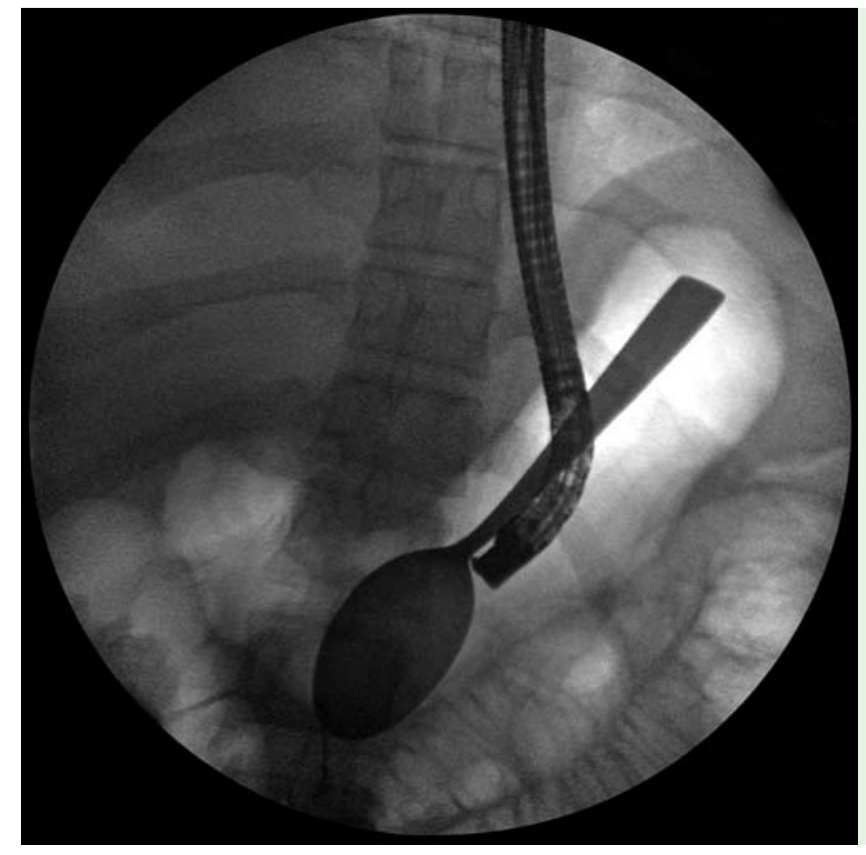

Fig. 4 Removal of the spoon under fluoroscopic guidance.

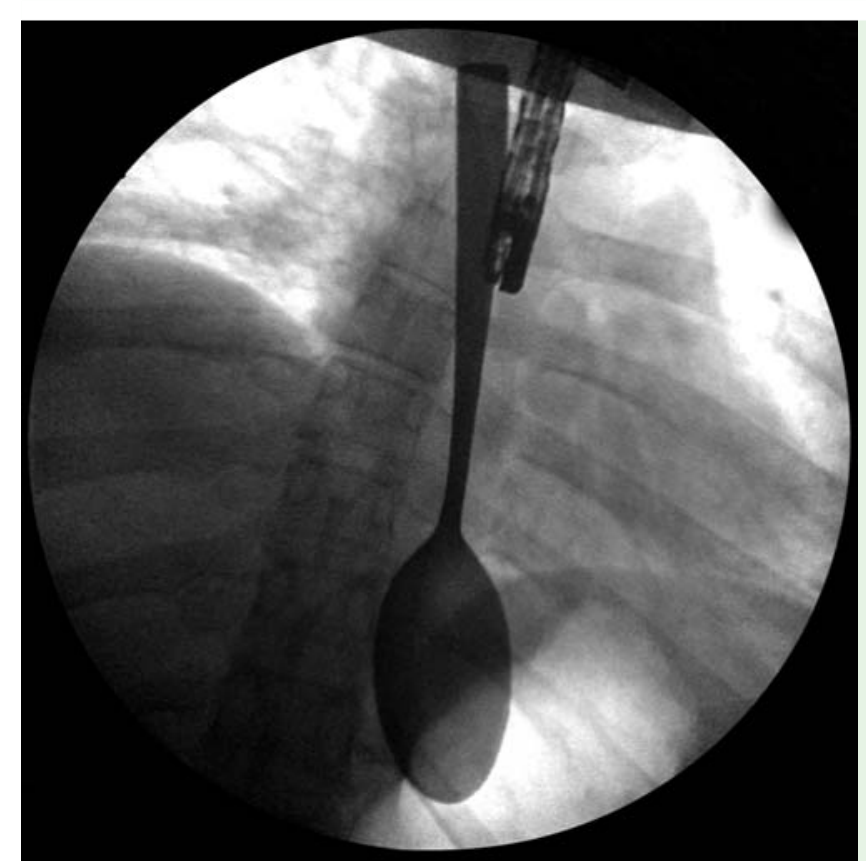

Fig. 5 Removal of the spoon under fluoroscopic guidance.

\section{I. El Hajj, B. W. Clarke, A. Slivka}

University of Pittsburgh Medical Center, Pittsburgh, Pennsylvania, USA

\section{References}

1 Eisen GM, Baron TH, Dominitz JA et al. American Society for Gastrointestinal Endoscopy. Guideline for the management of ingested foreign bodies. Gastrointest Endosc 2002; 55: $802-806$

2 Yong PT, Teh CH, Look $M$ et al. Removal of a dinner fork from the stomach by doublesnare endoscopic extraction. Hong Kong Med J 2000; 6: 319-321
3 Webb WA. Management of foreign bodies of the upper gastrointestinal tract: update. Gastrointest Endosc 1995; 41: 261 - 263

4 Aoyagi K, Maeda K, Morita I et al. Endoscopic removal of a spoon from the stomach with a double-snare and balloon. Gastrointest Endosc 2003; 57: 990 - 991

5 Chang DK, Ross WB. Endoscopic retrieval of a teaspoon from the stomach. ANZ J Surg 2004; 74: 1013-1014

6 Beldholm BR, Lee AU. Simple endoscopic technique for retrieving a long foreign body from the stomach. ANZ J Surg 2007; 77: 560-561

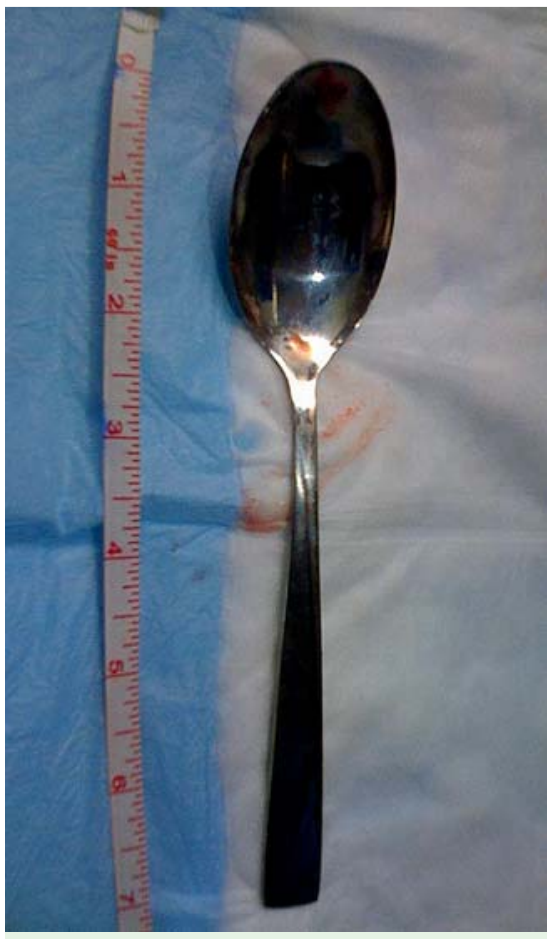

Fig. 6 Metal spoon after retrieval.

Bibliography

DOI $10.1055 / \mathrm{s}-0030-1256139$

Endoscopy 2011; 43: E107-E108

(c) Georg Thieme Verlag KG Stuttgart · New York . ISSN 0013-726X

\section{Corresponding author \\ B. Clarke, MD}

Department of Gastroenterology

University of Pittsburgh Medical Center

PUH, M2, C Wing

200 Lothrop St

Pittsburgh, PA 15213

USA

Fax: +1-412-648-9378

clarkebw@upmc.edu 